\title{
O método vivencial no campo das Habilidades Sociais: construção histórico-conceitual e sua aplicação
}

\section{The experiential method in the field of social skills: building historic-conceptual and its application}

\section{Talita Pereira Dias*}

Universidade Federal de São Carlos - UFSCar, São Carlos, SP - Brasil

\author{
Paula Almeida de Oliveira** \\ Universidade Federal de São Carlos - UFSCar, São Carlos, SP - Brasil
}

Maria Luiza Pontes de França Freitas***

Universidade Federal de São Carlos - UFSCar, São Carlos, SP - Brasil

\begin{abstract}
RESUMO
O Treinamento de Habilidades Sociais (THS) constitui um campo teóricoprático de conhecimento acerca do desempenho social. Além disso, é composto por diferentes abordagens teóricas e técnicas de intervenção nelas fundamentadas. Dentre os diferentes métodos utilizados no treinamento destaca-se o método vivencial, foco deste trabalho que tem como objetivo apresentar o processo de construção desse método, em termos teóricos e práticos, bem como em termos de sua concepção e utilização na atualidade. Propõe-se também realizar uma análise crítica pertinente a sistematização das vivências e ampliação do emprego das mesmas favorecendo o aprimoramento do método vivencial. Com base nas análises realizadas, pode-se supor que o método vivencial tende a se ampliar tanto na aplicação por profissionais da Psicologia e áreas afins, bem como em termos de sistematização do conhecimento produzido.
\end{abstract}

Palavras-chave: Habilidades sociais, Método Vivencial, História, Aplicação.

\begin{abstract}
The Social Skills Training (SST) is a theoretical and practical field of knowledge of social performance. Furthermore, it is composed of different theoretical approaches and intervention techniques based on them. Among the different methods used in training highlights the experiential method, focus of this paper, which aims to present the construction process of this method in theoretical and practical aspects and in terms of their design and use actually. It is also proposed to perform a critical analysis of the systematization of relevant experiences, as well as the expansion of employment of those favoring the improvement of the experiential method. Based on the analysis performed, one can assume that the experiential method tends to expand both in the application of professional psychology and related fields, as well as in terms of knowledge.
\end{abstract}

Keywords: Social Skills, Experiential Method, History, Application. 
O investimento na promoção de habilidades sociais tem sido apontado como importante para as diferentes fases do desenvolvimento desde a infância, passando pela adolescência, idade adulta e terceira idade. Essas habilidades contribuem para uma maior adaptação às demandas próprias de cada faixa etária e de diferentes contextos, proporcionando, assim, o desenvolvimento ou ampliação do repertório de comportamentos sociais.

A área de Habilidades Sociais, mais que um campo de aplicação, está embasada em conhecimento teórico e empírico acerca do desempenho social. Todavia, são escassos trabalhos de revisão histórico-conceitual no contexto brasileiro. Estudos nessa vertente contribuem para sistematizar conhecimento, realizar análise crítica e dialogar com outras disciplinas científicas e evidências empíricas, de modo a identificar lacunas e contribuir para avanços teóricos. Diante desse cenário, justifica-se o desenvolvimento de estudos teóricos.

Diferentes conceitos presentes no campo das Habilidades Sociais podem ser analisados a partir de uma revisão histórico-conceitual. Dentre eles verifica-se o conceito de vivências, apresentado e sistematizado por Del Prette e Del Prette (2001), Del Prette e Del Prette (2005) e Del Prette e Del Prette (2006).

O método vivencial se fundamenta, conforme Del Prette e Del Prette (2001) em várias premissas, tais como: (1) consiste em um dos recursos para o treinamento e avaliação das habilidades sociais; (2) propicia a superação de déficits e a promoção de habilidades sociais por desenvolver um ambiente de apoio mútuo; (3) cria oportunidade de observação, descrição e feedback dos desempenhos e experiências interpessoais por parte do terapeuta e demais participantes; (4) é concebido como um método de aprendizagem de habilidades sociais em grupo.

Com base nesse panorama, o presente artigo busca apresentar o processo de construção do método vivencial, bem como sua concepção e aplicação na atualidade. Para tanto, primeiramente apresenta-se um breve histórico do campo designado por Treinamento de Habilidades Sociais (THS), principais conceitos e procedimentos adotados. Em seguida, apresenta-se 0 método vivencial e sua trajetória histórico-conceitual, tomando como base as principais referências que abordam esse método. Busca-se, ainda, a partir da análise desses trabalhos, destacar alguns aspectos que poderiam ser considerados como antecedentes do método vivencial. Por fim, serão apresentados exemplos da aplicação de vivências em trabalhos atuais.

\section{Breve caracterização do campo: conceitos e histórico}

O Treinamento de Habilidades Sociais (THS) constitui um campo teórico-prático de conhecimento acerca do desempenho social (DEL PRETTE; DEL PRETTE, 1999) que é definido como qualquer 
comportamento social ou seqüência de comportamentos emitidos em situação social. Além do conceito de desempenho social, segundo Del Prette e Del Prette (1999; 2001; 2005), outros conceitos fundamentam o THS: como os de habilidades sociais e competência social. O primeiro, de acordo com os autores, tem um caráter mais descritivo e refere-se às classes de comportamentos sociais presentes no repertório do indivíduo que, se emitidos, contribuem para um desempenho socialmente competente. O segundo, competência social, em seu caráter avaliativo, consiste na capacidade de 0 indivíduo articular sentimentos, pensamentos e comportamentos, em função de objetivos pessoais e de demandas situacionais e culturais, que podem trazer conseqüências favoráveis a ele próprio e para sua relação com os outros (DEL PRETTE; DEL PRETTE, 2001). Considerando esses conceitos, um desempenho é avaliado como socialmente competente se atender aos seguintes critérios: consecução de objetivos da interação; manutenção ou melhora da auto-estima e da qualidade da relação; maior equidade de ganhos e perdas entre os envolvidos na interação; respeito e/ou ampliação dos direitos humanos básicos (DEL PRETTE; DEL PRETTE, 2001).

Referente à origem do campo das Habilidades Sociais, Caballo (1996) apresenta-a fundamentada em três vertentes científicas, além dos estudos clínicos que datam da década de trinta: (1) trabalhos de Salter (1949) e sua continuidade nos trabalhos de Wolpe e Lazarus, com a popularização da assertividade por Alberti e Emons, na década de 70, nos Estados Unidos; (2) trabalhos de Zigler e Phillips na década de 1960 com pacientes psiquiátricos institucionalizados; (3) estudos de Argyle (1967) sobre ergonomia e sistemas homemmáquina, relacionados a conceitos de habilidades sociais (DEL PRETTE; DEL PRETTE, 1996)

O panorama delineado por Caballo (1996) apresenta o THS derivado do Treinamento Assertivo, o que não é consensual. Para alguns autores como Del Prette e Del Prette (1996; 1999) e Falcone (2001), o THS tem sua origem nas obras de Argyle. Esses estudiosos identificam uma concomitância entre os enfoques da assertividade, que se originou nos Estados Unidos, e o das habilidades sociais, que se iniciou na Inglaterra, mais especificamente, com os trabalhos de Argyle, ao publicar o livro The psychology of interpersonal behavior em 1967.

Um pouco mais tarde, o THS chegou à América do Sul onde, apesar das dificuldades econômicas e políticas, pode-se verificar, conforme Del Prette e Del Prette (1996), sua disseminação em países como Chile (HIDALGO; ABARCA, 1990; 1991) e Colômbia (RISO, 1985). No Brasil, o primeiro trabalho relacionado à temática data da década de 70, que foi o estudo de A. Del Prette (1978). Destaca-se que eram escassos trabalhos nesta área na Psicologia em contexto nacional. Esse cenário começou a mudar a partir da década de noventa quando 
começaram a ser publicados artigos (DEL PRETTE; DEL PRETTE, 1996; DEL PRETTE; DEL PRETTE; BARRETO, 1999) e, principalmente, livros sobre habilidades sociais $e$ conceitos relacionados (DEL PRETTE; DEL PRETTE, 1999; DEL PRETTE; DEL PRETTE, 2001; DEL PRETTE; DEL PRETTE, 2005).

Atualmente, nota-se que esse campo ampliou-se consideravelmente por meio de publicação de trabalhos (FALCONE, 2001a; 2001b; 2002; RIBEIRO; COSTA; ARAÚJO, 2005; BANDEIRA; DEL PRETTE; DEL PRETTE; MAGALHÃES, 2009) que se dedicam tanto a avanços na base teórica quanto empírica e de aplicação. No contexto brasileiro, isso também ocorre como se constata no trabalho de revisão realizado por Bolsoni-Silva e cols. (2006), que afirmam ser o THS "um dos mais profícuos movimentos da Psicologia nas últimas décadas" (p. 1).

Bolsoni-Silva e cols. (2006) consideram o artigo "Habilidades sociais: Uma área em desenvolvimento" de Del Prette e Del Prette (1996) como o marco da apresentação desse campo de conhecimento e aplicação no Brasil. Essa publicação, embora não seja a primeira, é considerada um marco porque apresenta uma introdução geral ao campo teórico-prático das Habilidades Sociais, por meio de uma revisão bibliográfica extensa que permitiu explicitar aspectos de sua constituição, os principais conceitos, abordagens e os procedimentos de avaliação e de promoção do repertório de habilidades sociais.

No trabalho de Del Prette e Del Prette (1996), destaca-se a importância das interações sociais em diferentes contextos e apontase que dificuldades interpessoais relacionadas ao desempenho social inadequado refletem-se na qualidade das interações sociais. Nessa obra, ainda, são apresentados os diferentes modelos conceituais que embasaram a construção do campo das habilidades sociais, entre os quais: o cognitivo, o da teoria de papéis, o da assertividade, o da aprendizagem social e o da percepção social. Esses modelos estão na base de hipóteses explicativas para as habilidades sociais, bem como para estratégias de intervenção.

De acordo com vários autores (CABALLO, 1996; DEL PRETTE; DEL PRETTE, 1999; DEL PRETTE; DEL PRETTE, 2001; FALCONE, 2002), numa intervenção com THS são empregadas técnicas derivadas desses vários modelos conceituais, de modo que o THS vem se orientando para uma maior aproximação entre as abordagens, o que dificulta a distinção das especificidades de cada uma delas. Por exemplo, a dessensibilização sistemática, considerada estritamente comportamental pode apresentar algum correlato cognitivo de acordo com WOLPE em entrevista a Caballo e Simon (1995).

Existem muitas variações dessas técnicas e combinações diversas entre elas, dependendo do modelo adotado pelo terapeuta e do modo como este irá programar os procedimentos para intervenção. Outras técnicas, derivadas da Psicologia Social, que podem ser utilizadas no 
THS e no favorecimento da promoção dos desempenhos sociais são exposição oral, arranjos de grupos, simulações de desempenho e etc. Há, ainda o método vivencial que é foco do presente artigo, de modo que seu processo de construção será descrito a seguir.

\section{A construção do conceito de método vivencial}

O método vivencial, criado por Del Prette e Del Prette $(2000,2001$, 2005b, 2006) foi aprimorado enquanto técnica ao longo dos anos. Algumas das principais características deste método já estavam presentes em diversas publicações dos autores. No entanto, a definição conceitual foi publicada somente no livro de 2001, Psicologia das Relações Interpessoais: Vivências para o trabalho em grupo.

Considerando que Del Prette e Del Prette foram os proponentes do método vivencial, o presente trabalho tem como base as obras desses autores e colaboradores (por exemplo: DEL PRETTE, 1978; DEL PRETTE, 1985; DEL PRETTE; DEL PRETTE; BARRETO, 1999; DEL PRETTE; DEL PRETTE, 1999; DEL PRETTE; DEL PRETTE, 2000; DEL PRETTE; DEL PRETTE, 2001; DEL PRETTE; DEL PRETTE, 2005). A seguir cada uma dessas obras será apresentada e analisada criticamente a fim de explicitar as características ou concepções que mais tarde constituiriam o que atualmente é denominado método vivencial.

No trabalho de 1978, A. Del Prette propõe um treinamento comportamental para estagiários de Psicologia do hospital em uma universidade. Nessa proposta, fazem a referência ao procedimento de Psicodrama Comportamental, com algumas semelhanças com 0 método de dramatização desenvolvido por Moreno, como é o caso do desempenho de papéis. Contudo, o objetivo era a aprendizagem de comportamentos-alvo e não a catarse ou gerar emocionalidade, como no Psicodrama de Moreno. Pode-se destacar, nesse trabalho, a preocupação do autor com procedimentos de generalização dos comportamentos aprendidos a outros contextos propondo tarefas que deveriam ser emitidas fora da situação de treinamento. Ademais, verifica-se que o autor defende o formato de treinamento em grupo, considerando as possibilidades de aprendizagem por observação. Por fim, neste trabalho, o autor sugere que o treinamento não deve ser restrito à população com queixas clínicas, mas pode também ser utilizado com fins educativos ou de prevenção. Subentende-se que esses aspectos foram mais tarde focalizados em intervenções com 0 método vivencial.

No trabalho derivado de sua dissertação de mestrado, A. Del Prette (1985) propõe que, durante o treinamento, as cadeiras sejam dispostas em semi-círculos, o que indica sua preocupação em estruturar um ambiente mais favorável para as trocas entre os membros do grupo. O autor também aborda alguns procedimentos 
que foram adotados como, por exemplo, situações simbólicas e análogas ao cotidiano para o desempenho de papéis. Além disso, ele destaca como objetivo o "desenvolvimento dos sujeitos em termos de habilidades..." (p.46). Verifica-se que nesse trabalho não havia menção ao termo habilidades sociais. Na discussão sobre o treinamento, com base nas observações realizadas, o autor sugere que algumas habilidades atuam como pré-requisitos para outras mais complexas, recomendando um esboço de estruturação do treinamento: iniciar por habilidades mais simples para depois aprimorar ou promover aquelas mais complexas. Outro aspecto muito importante discutido no trabalho de 1985 diz respeito a variações de procedimento, conforme consta no trecho a seguir:

\begin{abstract}
Outra consideração a ser feita é com relação ao número de variações de procedimentos. Essas variações podem ser entendidas como um recurso para evitar a estereotipia natural quando da aprendizagem de novos comportamentos. Pode ser considerada, também uma estratégia para facilitar a generalização das habilidades aprendidas no treinamento (DEL PRETTE, 1985, p. 52)
\end{abstract}

Mais de uma década depois, o trabalho de Del Prette, Del Prette e Barreto (1999), desenvolvido com uma população universitária, também resultou em contribuições para a constituição do método vivencial. No contexto de uma disciplina ${ }^{1}$ para estudantes de Psicologia, as aulas foram divididas em dois módulos: um teóricoinformativo e outro prático no qual se utilizava diferentes técnicas presentes em um programa de THS. Comparando os alunos da disciplina (grupo experimental) e alunos da mesma turma que não participaram da disciplina (grupo controle). Os autores observaram que, embora no início ambos os grupos tivessem um repertório semelhante, ao final do programa de treinamento, o grupo experimental apresentou ampliação de repertório de habilidades sociais quando comparados ao grupo controle. É importante destacar que embora neste período o método vivencial não estivesse definido alguns de seus princípios foram aplicados e resultados positivos puderam ser observados.

Del Prette e Del Prette (1999), ao considerar o profissional que realiza o THS, questionam qual seria o melhor termo para se referir a esse profissional que conduz o grupo de treinamento, e discutem sobre algumas possibilidades como facilitador, dirigente ou terapeuta. Contudo, pode-se observar que ainda não é definido nessa obra qual o melhor termo a ser utilizado. Os autores discutem também as técnicas já presentes em um programa de THS e afirmam:

Algumas outras técnicas derivadas da Psicologia Social dos grupos e da educação podem ser usadas [...] exposição oral, 
dinâmicas de grupo, arranjos GV-GO (grupo de desempenho de vivência e grupo de observação), atividades cooperativas e simulações de desempenho [...] (p. 140)

Esse excerto sugere algumas técnicas que atualmente estão incorporadas ao método vivencial, como, por exemplo, a exposição oral, simulação de desempenho e outras, mas que na obra citada ainda não estavam sistematizadas desta forma. Outra aproximação ao conceito de vivências refere-se à menção de arranjo GV (grupo de vivência) e GO (grupo de observação), também amplamente adotado. Ao analisar esses aspectos verifica-se que refletem um crescente acúmulo de técnicas, estratégias, dados de observação que permitiriam a construção do que atualmente consiste em um método complementar ao THS.

No trabalho de Del Prette e Del Prette (2001b) com o título "O uso de vivências no THS", os autores destacam: "Após utilizar o método vivencial durante muitos anos, estamos sugerindo-o como um complemento importante ao formato usual do THS, em especial (mas não somente), quando aplicado à população sem queixa clínica" ( $p$. 122). Com base nessa afirmação, pode-se retomar a consideração de Del Prette (1978) sobre a possibilidade de treinamento para população não clínica. Além disso, presume-se que o método vivencial, embora muito presente na aplicação, ainda não havia sido sistematizado em termos conceituais. Acrescenta-se que na publicação de 2000, Del Prette e Del Prette afirmam também que a vivência consiste em um método de aprendizagem de habilidades sociais e não deve ser confundida com Psicodrama ou com a dinâmica de grupo por facilitar a promoção de habilidades específicas que podem ser organizadas em sequência gradualmente mais complexa de desempenhos interpessoais (DEL PRETTE; DEL PRETTE, 2005).

Ainda, Del Prette e Del Prette (2000) elencam alguns aspectos que devem ser considerados para a aplicação de vivências: estar adequada às demandas dos membros do grupo tanto quanto aos objetivos do treinamento como à complexidade; atentar para o envolvimento e participação dos membros do grupo; fortalecer os comportamentos de cooperação entre os membros; oportunizar comportamentos de observação e auto-observação e aprendizagem por meio de modelação e garantir a distribuição relativamente equivalente de atenção aos participantes. Nessa publicação é utilizado o termo terapeuta para se referir àquele que coordena o grupo de THS.

No que diz respeito à estruturação de um programa de THS que adota o método vivencial, os autores sugerem: 1) fase inicial, na qual as vivências ocupam grande parte da sessão no sentido de favorecer a coerência entre componentes conativos, cognitivos e afetivos; 2) fase intermediária, neste momento o uso das vivências deve ocorrer 
principalmente no início e término das sessões no sentido, respectivamente, de estimular ou preparar para a parte central do treinamento e de encerrar de modo confortável a sessão; e fase final em que é recomendável uma redução de adoção de vivências, ainda que sejam utilizadas àquelas relacionadas à aprendizagem de habilidades complexas e de reflexões existenciais sobre qualidade de vida e de relacionamento.

Na obra Psicologia das Relações Interpessoais: Vivências para o trabalho em grupo (DEL PRETTE; DEL PRETTE, 2001), que pode ser concebida como um marco para a consolidação do método vivencial no campo do THS, além de se considerar aspectos já citados no trabalho de 2000, retoma-se também a definição do conceito de vivências:

Atividade, estruturada de modo análogo ou simbólico a situações cotidianas de interação social dos participantes que mobiliza sentimentos, pensamentos e ações, com o objetivo de suprir déficits e maximizar habilidades sociais em programas de THS em grupo (p. 106).

Ao analisar essa obra constata-se que apresenta alguns avanços com relação às demais, como, por exemplo, a explicitação do significado do termo vivência e sua conceituação. Outro fato relevante consiste na apresentação de 40 vivências para se trabalhar habilidades sociais em diferentes fases do programa de THS (inicial, intermediária e final), principalmente com a população adulta e adolescente.

No trabalho de Del Prette e Del Prette (2005b), Psicologia das Habilidades Sociais na Infância, os autores retomam o conceito de vivências e propõem alguns complementos e alterações:

Atividade de grupo, estruturada de modo análogo ou simbólico a situações cotidianas, que cria oportunidades para desempenhos específicos, permitindo que 0 facilitador avalie os comportamentos observados e utilize as contingências pertinentes para fortalecer e/ ou ampliar o repertório de habilidades sociais dos participantes (grifo nosso, p. 101).

Ao comparar as duas definições do método vivencial, pode-se supor uma diferenciação com progresso na definição de 2005, uma vez que, nesta obra, a vivência é tida não só como um recurso para suprir déficits, mas também no sentido de oportunizar aprimoramento ou fortalecimento de habilidades sociais. Além disso, a vivência passa a ser considerada também com a função de método de avaliação dos comportamentos dos participantes. No livro citado, são propostas 20 vivências distribuídas entre as sete classes de habilidades sociais presentes na infância: empatia; civilidade; assertividade; autocontrole e expressividade emocional; habilidades sociais 
acadêmicas; de fazer amizades e solução de problemas. Comparada à descrição de estrutura de programa de THS na obra de 2001, no trabalho de 2005 é observado um maior detalhamento quanto à estruturação, organização e condução do processo de intervenção em THS que utiliza o método vivencial.

Com base no conjunto de trabalhos, é possível observar que na década de 70 já se identificava aspectos característicos do que seria, mais tarde, chamado de método vivencial. Contudo, desde 1978 até os dias atuais, uma série de mudanças, complementações e aprimoramento nas técnicas e procedimentos favoreceram a construção e operacionalização do método vivencial. As diretrizes para aplicação e a maior utilização desse método nos programa de THS serão foco do tópico a seguir.

\section{Uso atual do método de vivência}

Atualmente, as vivências têm estrutura e características específicas. Estudos têm implementado esse procedimento e demonstrado sua viabilidade em termos de promoção de habilidades sociais, tanto com adultos (DEL PRETTE; DEL PRETTE, 2001) como com crianças (DEL PRETTE; DEL PRETTE, 2005).

Quanto à sua estrutura, as vivências estão sistematizadas em roteiros de condução que constam dos seguintes tópicos (DEL PRETTE; DEL PRETTE, 2001; DEL PRETTE; DEL PRETTE, 2005): título; objetivos; materiais; procedimento; observações e variações (sugestões de outros procedimentos que podem ser complementares ou substitutivos). No que se refere às condições favorecidas pelas vivências em um programa de THS, A. Del Prette e Del Prette (2001) e Z. Del Prette e Del Prette (2005) destacam as seguintes possibilidades: (a) observar o desempenho em diferentes situações e papéis, com vistas a avaliar déficits, recursos, aquisições, entre outros; (b) identificar situações que possam produzir ansiedade, estimulando o relato de eventos encobertos (pensamentos, sentimentos, etc.); (c) aumentar gradativamente a complexidade da tarefa para fortalecer desempenho e tornar mais provável sua generalização; (d) estabelecer, disponibilizar ou mediar conseqüências positivas para os desempenhos esperados ou, ao menos, mais próximos do desempenho-alvo; (d) ampliar o conhecimento sobre a cultura do grupo; (e) conduzir diferentes tipos de vivências, com habilidades objetivadas semelhantes, com vistas a garantir generalização.

Contudo, para que essas condições realmente ocorram, é importante que os facilitadores atendam a requisitos importantes, conforme apontam Del Prette e Del Prette (2001) e Del Prette e Del Prette (2005). Entre os requisitos destacados, tem-se: qualificação na área; conhecimento sobre princípios de aprendizagem; participação no planejamento do programa; conhecimento da clientela e respeito aos 
princípios éticos. Além das condições do facilitador, outros requisitos, durante a condução das vivências, devem ser atendidos, entre os quais: favorecer que todos os membros participem da atividade; oferecer igualdade de oportunidades aos participantes; aproveitar todo o potencial da vivência, motivando e incentivando a aprendizagem gradual de novos comportamentos; incentivar a cooperação entre os participantes (DEL PRETTE; DEL PRETTE, 2001; DEL PRETTE; DEL PRETTE, 2005).

Segundo Del Prette e Del Prette (2001) e Del Prette e Del Prette (2005) para a seleção das vivências que serão utilizadas durante o programa, é necessário considerar os seguintes aspectos: necessidades e potencialidades gerais do grupo; necessidades e potencialidades específicas de cada indivíduo. Para a organização das vivências, é importante considerar a complexidade das atividades, iniciando com objetivos e atividades mais simples e gradualmente passar para as mais complexas, avaliando sempre os avanços comportamentais dos participantes.

Com relação aos trabalhos que adotaram o método vivencial, o estudo de Del Prette e Del Prette (2006) intitulado Treinamento em Habilidades Sociais: o método vivencial e a participação do professor apresenta um programa de THS. Esse programa utilizou o método vivencial com crianças e foi implantado em uma escola pública por professores previamente treinados para atuarem como facilitadores. Os resultados do estudo permitem concluir, entre outros aspectos, que a utilização das vivências: foi reconhecida pelas professoras como uma ferramenta que contribuiu para melhorar a relação delas com seus alunos; foi bem aceita pelos professores; apresentou-se como possível no contexto escolar sem que houvesse uma sobrecarga de tarefas para o professor.

Outro trabalho que também empregou o método vivencial foi realizado por Pinheiro, Haase, A. Del Prette, Amarante e Del Prette (2006). Esse estudo descreve um programa de treinamento de habilidades sociais para pais de crianças com problemas de comportamento. A utilização das vivências teve como objetivos: (1) possibilitar aos pais a identificação de comportamentos em desacordo com o esperado ou combinado com os filhos e como esses comportamentos são controlados pela atenção; (2) desenvolver ou aprimorar, nos pais, habilidades de feedback, elogio, comunicação empática e observação e descrição de desempenho, entre outras. Quanto aos resultados, nos depoimentos apresentados pelos pais ao final do programa (todos valorizando os resultados obtidos), foram identificados relatos ilustrativos de mudanças na qualidade do seu relacionamento com os filhos e melhora nos comportamentos das crianças.

O trabalho de Lopes (2009) objetivou avaliar os efeitos de um programa de Treinamento de Habilidades Sociais e envolveu 
principalmente o Recurso Multimídia de Habilidades Sociais para Crianças (2005b) utilizado por crianças com dificuldades de aprendizagem. Além do RMHSC-Del-Prette (2005b), outros procedimentos pertinentes ao campo das habilidades sociais foram empregados como as vivências contidas no livro Psicologia das Habilidades Sociais na Infância. Após a intervenção, as crianças foram reavaliadas e em relação à avaliação contínua, foi possível verificar que à medida que as habilidades sociais eram ensinadas os participantes as adquiriram - ou aperfeiçoaram - e as mantiveram ao longo do THS.

Ainda, o estudo de Rocha (2009) envolveu um programa de promoção de habilidades sociais junto aos pais de crianças com Transtorno de Déficits de Atenção e Hiperatividade (TDAH), e teve por objetivo avaliar seus efeitos em termos de desempenho acadêmico e social dos filhos. Neste programa, as vivências foram empregadas como método para a observação direta do desempenho e como condição para o emprego de técnicas e procedimentos comportamentais, conforme sugerido por Z. Del Prette e Del Prette (1999). Os resultados mostraram que o programa foi efetivo em promover mudanças significativas para as mães do grupo experimental, principalmente naquelas habilidades que foram alvo da intervenção. As diferenças entre os grupos, experimental e de controle, mostraram impacto sobre o comportamento das mães e das crianças. Rocha e Del Prette (2010) em artigo teórico destacam a importância do método vivencial, em concomitância com outros procedimentos, para efetividade de programas de habilidades sociais. Em estudo mais recente, abordando o método vivencial sob a perspectiva da Análise do Comportamento, Del Prette e Del Prette (2010) destacam e detalham as características deste método em função de: (a) questões éticas e competência social; (b) estrutura baseada em vivências; (c) variabilidade comportamental; (d) exposição e sensibilidade às contingências em sessão; (e) foco nas habilidades de processo; ( $f$ ) treino de análise funcional $e$ automonitoria e $(\mathrm{g})$ tarefas de casa (genérica e personalizada).

Para finalizar, é importante destacar que o método vivencial tem sido utilizado também por pesquisadores argentinos. Um exemplo é um estudo comparativo entre grupos, formados por estudantes de psicologia, que avaliou medidas de auto-eficácia por meio da Escala de Autoeficacia Social para Universitarios (EAS-U). Um grupo participou do treinamento instrucional de habilidades sociais e outro grupo na modalidade de treinamento que envolvia vivências (MEDRANO; MIRANTES; GODOY; CABANILLAS; OLAZ, 2009). Os resultados mostraram que o grupo experimental que participou de vivências obteve pontuações significativamente mais altas e foram observadas diferenças significativas entre pré e pós-teste em todas as subescalas e escores da escala completa da EAS-U. Por fim, os 
autores concluem que os resultados permitem inferir que o programa de intervenção foi eficaz para fortalecer as crenças de auto-eficácia social dos estudantes.

\section{Considerações finais}

Com base na trajetória histórica delineada foi possível explicitar que o método vivencial nos programas de habilidades sociais está em construção desde as primeiras publicações de Del Prette e Del Prette (1978; 1985; 1999; 2001; 2005). Nesse percurso histórico, observase que a sistematização, consolidação e aprimoramento desse método foram decorrentes de observações detalhadas e análises críticas das aplicações em diferentes programas de THS, ao longo dos anos. Toda essa evolução conceitual em termos de definição do conceito e estruturação mais específica dos procedimentos deles decorrentes favoreceu a difusão de sua prática, o que é evidenciada por estudos que adotam tal método. Esses estudos que utilizaram vivências, unicamente ou combinada a outros recursos, no geral, demonstraram a efetividade desse método na promoção de habilidades sociais e atenuação dos déficits durante o THS.

Desse modo, pode-se supor que o método vivencial tende a se ampliar tanto na aplicação por profissionais da Psicologia e áreas afins, bem como em termos de sistematização do conhecimento produzido. Como observado, os estudos que o empregam se restringem a uma pequena parcela de pesquisadores, contudo os benefícios e vantagens que o método vivencial pode proporcionar sugerem a ampliação do emprego desse método, favorecendo assim a complementação e aprimoramento do mesmo, contribuindo para seu valor empírico e rigor metodológico.

\section{Referências Bibliográficas}

ARGYLE, M. La habilidade social. In: ARGYLE, M. Psicologia del comportamiento interpersonal. Madrid: Alianza Universidad, 1967/1994. p. 58-77.

BANDEIRA, M.; DEL PRETTE, Z. A. P.; DEL PRETTE, A.; MAGALHÃES,

T. (2009). Validação das escalas de habilidades sociais, Comportamentos problemáticos e competência acadêmica (SSRS-BR) no ensino fundamental. Psicologia: Teoria e Pesquisa, Brasília v. 25, n. 2, p. 271-282, abril/junho 2009.

BOLSONI-SILVA, A. T. B.; DEL PRETTE, Z. A. P.; DEL PRETTE, G.; MONTAGNER, A. R.; BANDEIRA, M.; DEL PRETTE, A. Habilidades sociais no Brasil: Uma análise dos estudos publicados em periódicos. In: BANDEIRA, M.; DEL PRETTE, Z. A. P.; DEL PRETTE, A. (Org.). Estudos sobre habilidades sociais e relacionamento interpessoal. São Paulo: Casa do Psicólogo, 2006. p. 17-45. 
CABALLO, V. E. O treinamento em habilidades sociais. In: CABALLO, V.E. (Org.). Manual de técnicas de terapia e modificação de comportamento. São Paulo: Livraria Santos Ed., 1996. p. 361-398. DEL PRETTE, A. O treino assertivo na formação do psicólogo. Arquivos Brasileiros de Psicologia Aplicada, Rio de Janiero, v. 30, p. 53-55, Jan/J un, 1978.

DEL PRETTE, A. Treinamento comportamental em grupo: Uma análise descritiva de procedimento. Psicologia USP, São Paulo, vol. 11, n. 2, p. 39-54, 1985.

DEL PRETTE, A.; DEL PRETTE, Z. A. P. Análise de repertório assertivo em estudantes de psicologia. Revista de Psicologia, v. 1, n. 1, p. 15-24, 1983.

- Habilidades sociais e construção de conhecimento em contexto escolar. In: ZAMIGNANI, D. R. (Org.). Sobre comportamento e cognição: A aplicação da Análise do Comportamento e da Terapia Cognitivo-Comportamental no hospital geral e nos transtornos psiquiátricos (vol. 3). São Paulo: AirBytes, 1997. p. 234-250.

. Psicologia das relações interpessoais: Vivências para o trabalho em grupo. 6ed. Petrópolis, RJ: Vozes, 2001 a.

- Aprendizagem socioemocional na escola e prevenção da violência: Questões conceituais e metodologia de intervenção. In: (Orgs.). Habilidades sociais, desenvolvimento e aprendizagem: Questões conceituais, avaliação e intervenção. Campinas: Alínea, 2003. p. 83-127.

.Treinamento assertivo, ontem e hoje. In: COSTA, C. E.; L'ŪZIA, J. C. ; SANT'ANNA, H. H. N. (Orgs.). Primeiros passos em análise do comportamento. Santo André: ESETec, 2003a. p. 149160.

Assertividade, religiosidade, muita além de uma rima. In: BRANDÃO, M. Z. S.; CONTE, F. C. S (Org). Falo ou não falo: expressando sentimentos e comunicando idéias. Arapongas: Mecenas, 2003b. p. 141-157.

. Treinamento em Habilidades Sociais: o método vivencial e a participação do professor. In: BANDEIRA, M.; DEL PRETTE, Z. A. P.; DEL PRETTE, A. (Orgs.). Estudos sobre Habilidades Sociais e Relações Interpessoais. São Paulo: Casa do Psicólogo, 2006. p. 143-159.

Del PRetTe, A.; Del PRetTe, Z. A. P.; BARReto, M. C. M. Habilidades sociales en la formación del psicólogo: Análisis de un programa de intervención. Psicologia Conductual, Granada, v. 7, n. 1, p. 27-47, 1999.

DEL PRETTE, Z. A. P. Uma análise descritiva dos processos comportamentais em um programa de treinamento em grupo. Psicologia USP, São Paulo, v. 11, n. 1, p. 45-63, 1985. 
DEL PRETTE, Z. A. P.; DEL PRETTE, A. Habilidades sociais: Uma area em desenvolvimento. Psicologia: Reflexão e Crítica, Porto Alegre, v. 9, n. 2, p. 287-389, maio/agosto 1996.

Psicologia das habilidades sociais: Terapia e educação. Petrópolis: Vozes, 1999.

. Treinamento em habilidades sociais: Panorama geral da área. In: HAASE, V. G.; ROTHE-NEVES, R.; KÄPLER, C.; TEODORO, M. L. M.; WOOD, G. M. O. (Org). Psicologia do Desenvolvimneto: Contribuições Interdisciplinares. Belo Horizonte: Health, 2000. p. 249-264.

. O uso de vivências no THS. In: MARINHO, M. M.; CABALLO, V. E. (Orgs.). Psicologia Clínica e da Saúde. Londrina: Editora UEL/APICSA, 2001b. p. 117-135.

- Treinamento de habilidades sociais com crianças: Como utilizar o método vivencial. In COSTA, C.E.; LUZIA, J. C.; SANT' ANNA, H. H. N. (Org.). Primeiros passos em Análise do Comportamento e Cognição. (vol. 2). Santo André: ESETec, 2004. p. 111-119.

. Grupo RIHS: Relações interpessoais e Habilidades Sociais. In: WORKSHOP DE GRUPOS DE PESQUISA, 2. E JORNADA CIENTÍFICA DA UFSCar, 6., 2005, São Carlos. Resumos. São Carlos: UFSCAR, 2005, p. 1.

Psicologia das habilidades sociais na infância: Teoria e Prática. 1. ed. Petrópolis: Vozes, 2005b.

DEL PRETTE, A.; DEL PRETTE, Z. A. P. Programa vivencial de habilidades sociais: características sob a perspectiva da Análise do Comportamento. In: GARCIA, M. R.; ABREU, P.; CILLO, E. N. P.; FALEIROS, P. B.; QUEIROZ, P. P. (Org.). Comportamento e Cognição: terapia comportamental e cognitiva. (vol. 27). Santo André, ESETec, 2010. p. 127-139.

FALCONE, E. M. O. Habilidades sociais para além da assertividade. In: Wielenska, R. C. (Org.). Sobre Comportamento e Cognição: questionando e ampliando a teoria e as intervenções clínicas e em outros contextos. (vol. 6). Santo André, ESETec, 2001a. p. 202-212.

Uma proposta de um sistema de classificação das hábilidades sociais. In: GUILHARDI, H. J.; MADI, M. B. B. P.; QUEIROZ, P. P.; SCOZ, M. C. (Org.). Sobre Comportamento e Cognição: expondo a variabilidade. (vol. 8). Santo André, ESETec, 2001b. p. 195-209.

Contribuições para o treinamento em habilidades de interação. In: GUILHARDI, H. J.; MADI, M. B. B. P.; QUEIROZ, P. P.; SCOZ, M. C. (Org.). Sobre Comportamento e Cognição: contribuições para a construção da teoria do comportamento. (vol. 9). Santo André, ESETec, 2002 p. 91-104.

LOPES, D. C. Recursos multimídia na promoção de habilidades sociais em crianças com dificuldades de aprendizagem. 2009. 
232f. Dissertação (Mestrado em Educação Especial) - Curso de Pós Graduação em Educação Especial, Universidade Federal de São Carlos, São Carlos, SP.

MEDRANO, L.; MIRANTES, R.; GODOY, J. C.; CABANILLAS, G.; OLAZ, $F$. O. Análisis del impacto de un programa de entrenamiento para la adquisición de habilidades sociales necesarias en La formación del psicólogo. In: II Seminário Internacional de Habilidades Sociais, 2009, Rio de Janeiro. Anais do II SI HS. Rio De J aneiro: UERJ, 2009. p. 180.

MURTA, S. G. Aplicações do treinamento em habilidades sociais: análise da produção nacional. Psicologia: Reflexão e Crítica, Porto Alegre, v. 18, n. 2, p. 283-291, maio/agosto 2005.

PINHEI RO, M. I. S.; HAASE, V. H.; DEL PRETTE, A.; AMARANTE, C. L. D.; DEL PRETTE, Z. A. P. Treinamento de habilidades sociais educativas para pais de crianças com problemas de comportamento. Psicologia: Reflexão e Crítica, Porto Alegre, v. 19, n. 3, p. 407414, setembro/dezembro 2006.

RIBEIRO, M. J. F. X.; COSTA, M. R.; ARAÚJO, E. A. S. Competência social, técnicas de avaliação e de intervenção em treinamento de habilidades sociais: a integração necessária. In: GUILHARDI, H. J.; AGUIRRE, N. C. (Org.). Sobre Comportamento e Cognição: expondo a variabilidade. v. 16. Santo André, ESETec, 2005. p. 59-69. ROCHA, M. M. (2009). Programa de habilidades sociais com pais: Efeitos sobre desempenho social e acadêmico de filhos com TDAH. 2009. 235 f. Tese (Doutorado em Educação Especial) Programa de Pós-Graduação em Educação Especial, Universidade Federal de São Carlos, São Carlos, SP.

ROCHA, M. M.; DEL PRETTE, Z. A. P. Habilidades sociais educativas para mães de crianças com TDAH e a inclusão escolar. Psicologia Argumento, Curitiba, v. 28, n. 60, p. 31-41, janeiro/março 2010.

\section{Endereço para correspondência}

Talita Pereira Dias

Universidade Federal de São Carlos, CECH, Departamento de Psicologia. PPGPsi. Via Washington Luiz, km 235, Laboratório de Interação Social (LIS), Grupo RIHS, Campus Universitário, CEP 13565-905, São Carlos - SP, Brasil

Endereço eletrônico: talitapsi10@yahoo.com.br

Paula Almeida de Oliveira

Universidade Federal de São Carlos, CECH, Departamento de Psicologia. PPGPsi. Via Washington Luiz, km 235, Laboratório de Interação Social (LIS), Grupo RIHS, Campus Universitário, CEP 13565-905, São Carlos - SP, Brasil

Endereço eletrônico: paulapsy@gmail.com

Maria Luiza Pontes de França Freitas

Universidade Federal de São Carlos, CECH, Departamento de Psicologia. PPGPsi. Via Washington Luiz, km 235, Laboratório de Interação Social (LIS), Grupo RIHS, Campus Universitário, CEP 13565-905, São Carlos - SP, Brasil

Endereço eletrônico: mluizapf@yahoo.com.br 
Talita Pereira Dias, Paula Almeida de Oliveira, Maria Luiza Pontes de França Freitas

Recebido em: 08/06/2010

Reformulado em: 10/09/2010

Aceito para publicação em: 10/09/2010

Acompanhamento do processo editorial: Adriana Benevides Soares

\section{Notas}

* Mestre em Psicologia pelo Programa de Pós-Graduação em Psicologia da UFSCar; Doutoranda no Programa de Pós-Graduação em Psicologia da Universidade Federal de São Carlos - UFSCar

** Mestre pelo Programa de Pós-Graduação em Psicologia da Universidade Federal de São Carlos - UFSCar

***Mestre em Educação Especial; Doutoranda no Programa de Pós-Graduação em Psicologia da Universidade Federal de São Carlos - UFSCar

${ }^{1}$ A disciplina faz parte da grade de optativas do curso de Psicologia da Universidade Federal de São Carlos e é ministrada por Almir e Zilda Del Prette. 